\title{
TORQUE REDUCTION CONTROL FOR AN ELECTRO- PNEUMATIC HYBRID VERTICAL POSITIONING SYSTEM
}

\author{
Hiroshi HIGO*, Yasuo SAKURAI**, Kazuhiro TANAKA*, Takeshi NAKADA*** \\ * Department of Mechanical Information Science and Technology, \\ Kyushu Institute of Technology \\ 680-4 Kawatsu, Iizuka, Fukuoka, 820-8502 Japan \\ ** Department of Mechanical Engineering, \\ Ashikaga Institute of Technology \\ 286-1 Oomae, Ashikaga, Tochigi, 326-8558 Japan \\ *** Department of Environment Integration and design, \\ Tokyo Denki University \\ 2-1200 Muzaigakuendai, Inzai, Chiba, 270-1382 Japan
}

\begin{abstract}
This paper deals with torque reduction control for an electro-pneumatic hybrid vertical positioning system composed of a servomotor a pneumatic and a mechanical driving sub-system. The servomotor, coupled with a ball screw connected to the load by nut, enables to position a load vertically. The servomotor with small capacity, as well as energy saving, is required for cost down. To realize its small capacity, it is important to reduce the torque of the servomotor in moving the load. In a pneumatic system, a pressure controller generates control signals for the supplied pressure equivalent to the gravitational force of the mass of the load so as to support and move the load smoothly. The torque reduction for the small capacity servomotor needs adequate control pressure supplied to a cylinder. In the present study, a mathematical model of this system has been developed by comparing calculation data with experimental results. The controller designed by this model has succeeded in the torque reduction of the servomotor.
\end{abstract}

\section{KEY WORDS}

Electro-pneumatic hybrid positioning system, Dynamic characteristics, Pressure control, Bondgraphs, Modeling

\section{NOMENCLATURE}

$A_{r}:$ Area of rod side cylinder

$A_{h}$ : Area of head side cylinder

$C$ : Frictional loss coefficient

$F$ : Force

$g$ : Gravity acceleration

$K$ : Rigidity of coupling

$I z$ : Momentum of shaft

$l$ : Lead of ball screw

$M:$ Inertial mass

$P$ : Pressure

$Q$ : Flow rate

$r_{0}:$ Diameter of ball screw

$v$ : Velocity

$\omega:$ Rotational speed

$\tau$ : Torque $\left[\mathrm{m}^{2}\right]$

$\left[\mathrm{m}^{2}\right]$

[Ns/m]

[N]

$\left[\mathrm{m} / \mathrm{s}^{2}\right]$

$[\mathrm{Nm} / \mathrm{rad}]$

$\left[\mathrm{kgm}^{2}\right]$

[m]

[kg]

[Pa]

$\left[\mathrm{m}^{3} / \mathrm{s}\right.$ ]

[m]

$[\mathrm{m} / \mathrm{s}]$

$[\mathrm{rad} / \mathrm{s}]$

$[\mathrm{Nm}]$

\section{INTRODUCTION}

A pneumatic cylinder has a difficulty to perform constant-speed drive and intermediate halt such as a hydraulic cylinder due to the compressibility that the air has [1-2]. Therefore, most of pneumatic cylinders are used with full strokes. A pneumatic servomotor to perform highly precise positioning has been developed however its control is complicated and positioning time becomes longer as a disadvantage.

Therefore, in recent years, electro-pneumatic hybrid actuators have been developed to break off this weak point [3]. An atmospherics hybrid actuator has a mechanism in which an AC servomotor is used with a pneumatic cylinder, perform positioning of a cylinder by a servomotor and support loads by air pressure. In the case this actuator is applied to a transport system, 


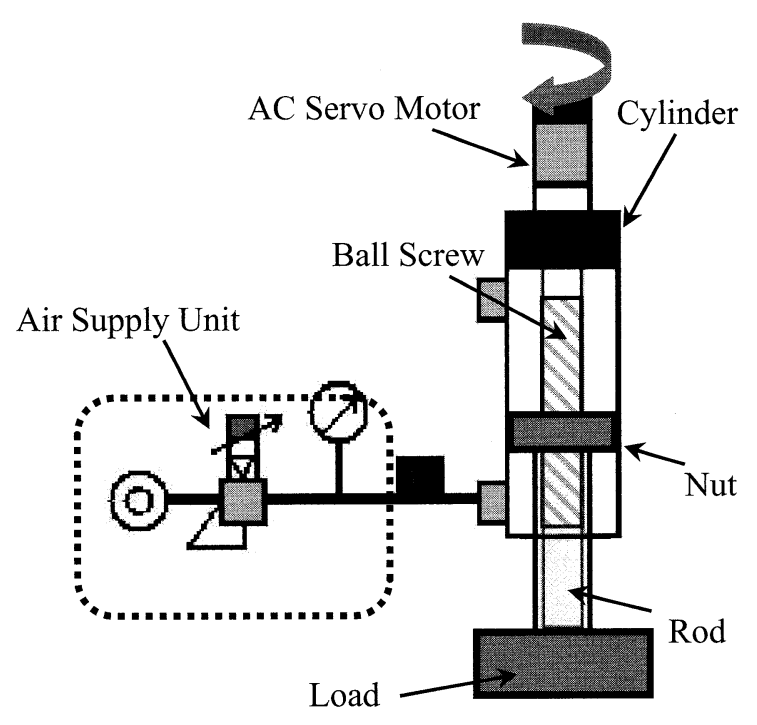

Figure 1 Electro-pneumatic actuator

precise positioning for a heavy load can be performed with a small capacitance motor. Therefore transport systems with low power can be realized with low cost. When an electro-pneumatic hybrid actuator is used under the condition that a load does not vary, it usually works with constant pneumatic pressure. However, when a load varies during an operation, control pneumatic pressure must be controlled depending on loads. At this time, unless the pressure control of a pneumatic cylinder is appropriate, torques more than the allowable value act on a servomotor and the actuator becomes uncontrollable. Furthermore, it may lose its control.
In this study, to solve the above problem, the authors propose a feedback technique to constantly minimize torques acting on a servomotor based on the analytical model [4] of this actuator control system already proposed. Furthermore, we perform control experiment to verify adequacy of this control method and confirm about the torque reduction effect.

\section{EXPERIMENTAL APPARATUS}

\section{Electro-pneumatic Hybrid actuator}

The electro-pneumatic hybrid actuator used for our experiment consisted of an AC servomotor, a cylinder, ball screw, hollow rod and pneumatic pressure feeding section as shown in Figure 1. The rotating shaft of the ball screw is connected with a servomotor by coupling and a hollow rod is connected with a nut.

When the servomotor runs and ball screw turns, the rod moves up and down. On the other hand, loads are supported by pneumatic pressure supplied from the rod side of the cylinder and even a low volume servomotor can move heavy loads precisely with this mechanism.

\section{Experimental system}

Figure 2 shows experimental apparatus used for our experiments. An AD converter, DA converter and motor controller are incorporated in a PC.

The servomotor can rotate with constant angular velocity with control signals from the motor controller. Pressure of the pneumatic cylinder and torques of the servomotor are measured by the AD converter. Operating an electro-pneumatic regulator with the $\mathrm{PC}$, pressure is controlled by the pneumatic regulator. Load Mass 1 is set on the rod of the electro-pneumatic hybrid actuator as shown in the Figure 2. Load Mass 1 is supported by pneumatic pressure and rises in constant speed with the servomotor. When an actuator rises by $20 \mathrm{~cm}$, Load Mass 2 on the table is loaded and both

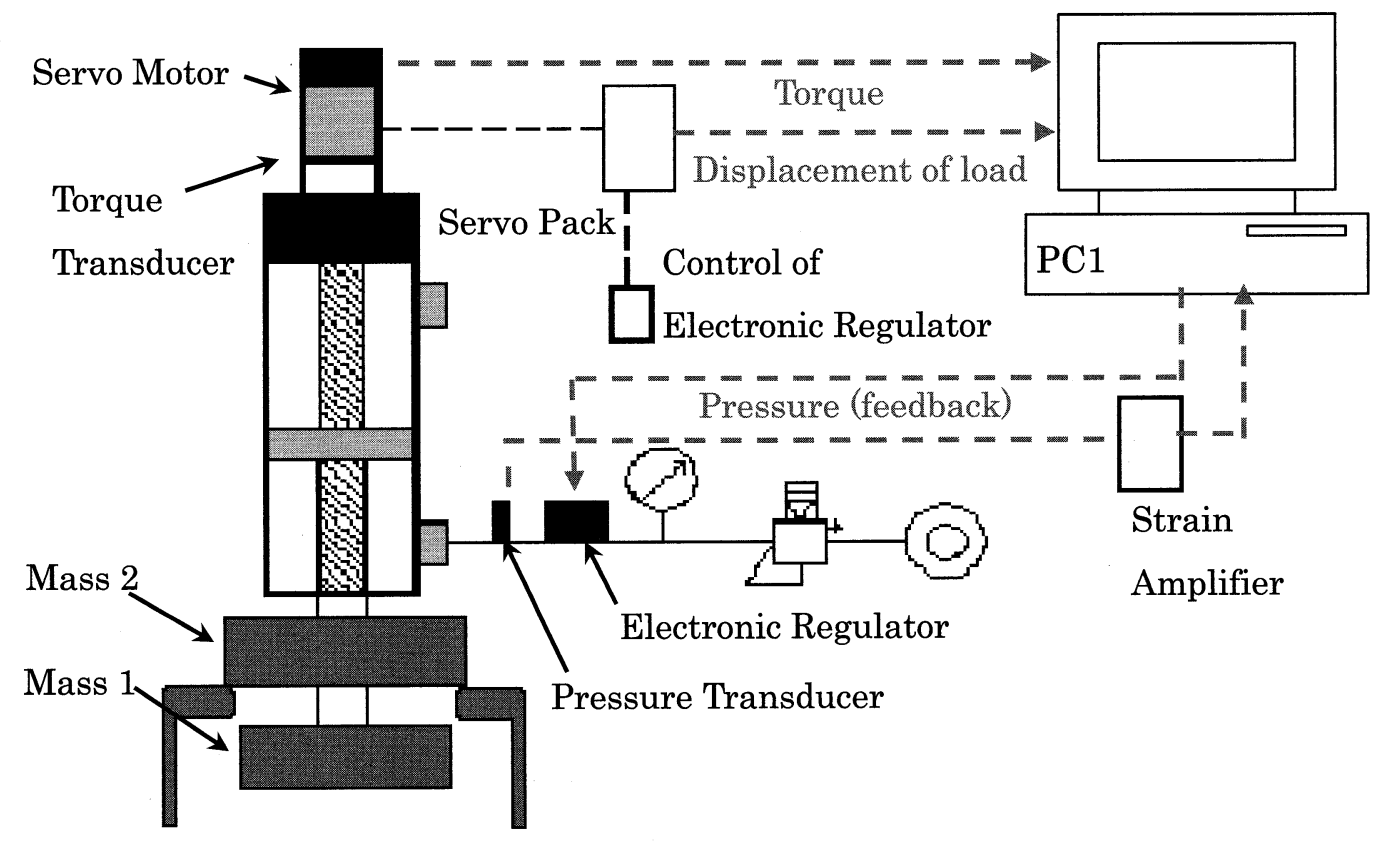

Figure 2 Experimental Equipment 


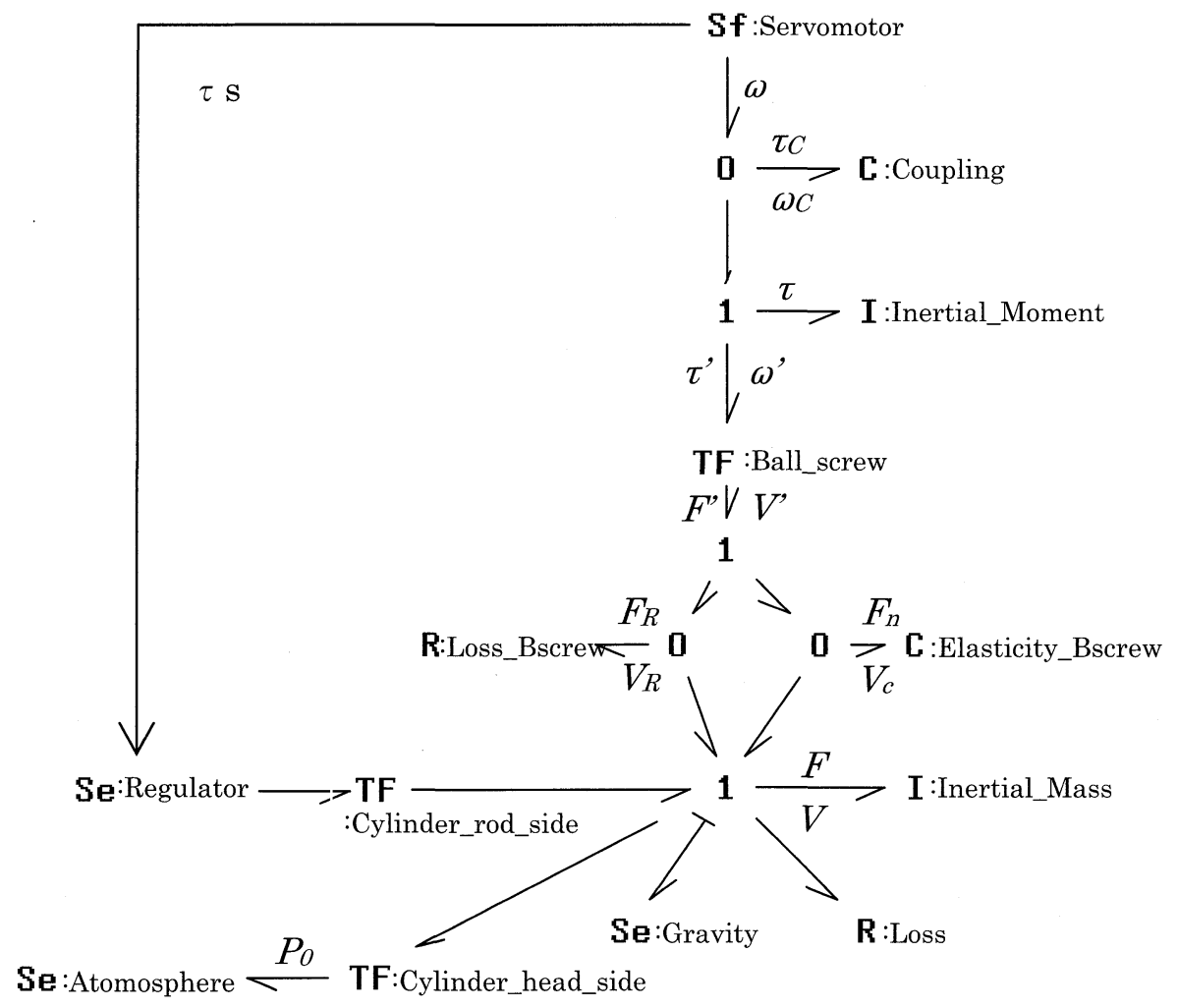

Figure 3 Bond graph model

Mass 1 and Mass 2 act on the actuator.

\section{Feed back control}

Torque acting on the servomotor is output as an electrical signal and acquired by a built-in AD converter incorporated in the PC. A pressure value $\mathrm{P}$ of the cylinder corresponded to the torque is calculated by Equation (1) and commands are transmitted to an electro-pneumatic regulator through a DA converter to control pressure of the pneumatic cylinder.

$$
P=P_{0}+\frac{2 \pi \tau}{A l}
$$

\section{SIMULATION}

\section{Analytical model}

We built an analytical model of our actuator control system. We used the bond graph approach as a simulation technique. The bond graph approach is one of the modeling techniques in which flow of power is focused and even a mixed system is expressed integrally as an advantage [5-7].

Figure 3 shows a system model of the electro-pneumatic hybrid actuator for which the experimental apparatus is expressed in the bond graph. A pneumatic cylinder transforms pneumatic pressure into a mechanical force therefore we modeled it by TF: Cylinder rod side element. An inertia of load, gravity and friction drag of a cylinder were modeled by I: Mass, Se: Gravity and R:
Loss elements, respectively. The head side of the pneumatic cylinder was opened to the atmospheric pressure therefore it was expressed by Se: Atmosphere element. On the other hand, a servomotor controls revolution speed therefore it was modeled by Sf: Motor element. Power supplied by a motor was affected by torsional rigidity and the rotating shaft's moment of inertia and was transmitted to the ball screw. The ball screw transformed rotary motions into linear motions therefore it was expressed by TF: Ball_Screw element. Effects of friction and an elasticity at the ball screw were modeled by C: Elasticity_Bscrew element and R: Loss_Bscrew element. To perform control, pressure values were calculated by substituting torques consumed in SF: Motor element into Equation (1). The torques were input as pressure values of Se: Regulator element. Pneumatic compressibility was not considered for this model.

\section{Property equation}

Property equations of each element used for this study are shown below.

TF: Cylinder_rod_side element,

$$
\begin{aligned}
& F=A P_{2} \\
& Q=A V
\end{aligned}
$$

Se: Gravity element

$$
F_{g}=M_{l} g
$$


$\mathrm{R}$ : Loss element

$$
\begin{aligned}
& (V<-0.01 \text { or } 0.01<V) \\
& F=C V \\
& (-0.01<V<0.01) \\
& F=\text { const. }
\end{aligned}
$$

It was difficult to theoretically obtain friction coefficient $\mathrm{C}$ used for the definitional equation of $\mathrm{R}$ : Loss element-type (8) therefore friction coefficient $\mathrm{C}$ was determined by the experiment in this study. Moreover, for a threshold value, we used the smallest traveling speed of the cylinder that could be measured in the experiment.

I: Inertia_Mass element

$$
V=\frac{1}{M_{l}} \int F d t
$$

C: Elasticity_Bscrew element

$$
F_{n}=K_{n} \int V_{c} d t
$$

R: Loss_Bscrew element

$$
F_{R}=C_{B} V_{R}
$$

TF: Ball_screw element

$$
\begin{aligned}
V^{\prime} & =\frac{l}{2 \pi} \omega^{\prime}=\frac{l}{2 \pi}\left(\omega-\omega_{c}\right) \\
\tau^{\prime} & =\frac{l}{2 \pi} F^{\prime}
\end{aligned}
$$

I: Inertial Moment element

$$
\begin{aligned}
& \omega^{\prime}=\frac{1}{I_{z}} \int \tau d t \\
& I_{z}=\frac{1}{2} M_{0} r_{0}{ }^{2}
\end{aligned}
$$

C: Coupling 素子

$$
\tau_{c}=K_{c} \int \omega_{c} d t
$$

\section{Sf: Servomotor element}

$$
\omega=\text { const }
$$

Analysis result and verification of adequacy Table 1 shows parameters analyses and experiments. Analysis and experimental results in the case that feedback control was performed are shown in Figure 4 and analysis and experimental results in the case that control was not performed are shown in Figure 5 . Comparing the two figures, it is understood that torques of a servomotor are reduced when feedback control is

\begin{tabular}{|c|c|c|}
\hline \multicolumn{2}{|l|}{ Parameters } & Value \\
\hline Valve effective area $\left[\mathrm{m}^{2}\right]$ & $A_{e}$ & $1.2 \times 10^{-5}$ \\
\hline Ratio of the specific heat of air $[-]$ & $K$ & 1.4 \\
\hline Initial temperature $[\mathrm{K}]$ & $T_{0}$ & 293 \\
\hline Gas constant $[\mathrm{J} / \mathrm{kg} \mathrm{K}]$ & $R$ & 287.3 \\
\hline Cross sectional area of cyl. $\left[\mathrm{m}^{2}\right]$ & $A$ & $2.6 \times 10^{-3}$ \\
\hline Supplied pressure $[\mathrm{MPa}]$ & $P_{1}$ & 0.224 \\
\hline Weight $[\mathrm{kg}]$ & $M_{l}$ & 31.7 \\
\hline Elasticity of the nut $[\mathrm{Nm} / \mathrm{rad}]$ & $K_{n}$ & $1.1 \times 10^{-8}$ \\
\hline Lead of the ball screw $[\mathrm{m} / \mathrm{r}]$ & $l$ & $10.0 \times 10^{-3}$ \\
\hline Inertial Moment $\left[\mathrm{kgm}^{2}\right]$ & $I_{z}$ & $4.06 \times 10^{-5}$ \\
\hline Elasticity of coupling [Nm/rad] & $K_{c}$ & 120.9 \\
\hline Rotational Velocity [rpm] & $\omega$ & 250 \\
\hline Mass $1[\mathrm{~kg}]$ & $m_{1}$ & 10 \\
\hline Mass $2[\mathrm{~kg}]$ & $m_{2}$ & 10 \\
\hline
\end{tabular}
performed. Similar results have been obtained from the analyses and experiments therefore it is understood that a control system of an electro-pneumatic hybrid actuator can be analyzed by this simulation model.

As a behavior of the servomotor's torques, it has been understood that at first, a large torque acts on a servomotor with a constant load when it begins rising and then it rises with a constant torque. Subsequently, a large torque acts on the servomotor when the load suddenly changes and then the load rises with a constant torque.

Table 1 Simulation parameters

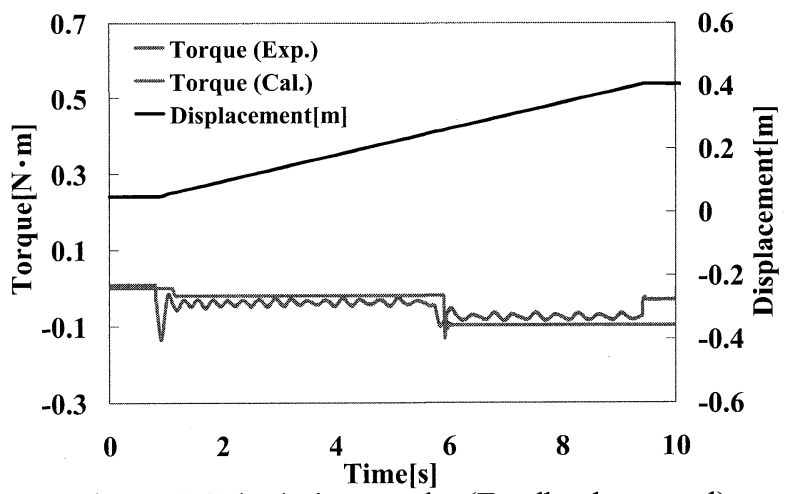

Figure 4 Calculation results (Feedback control) 


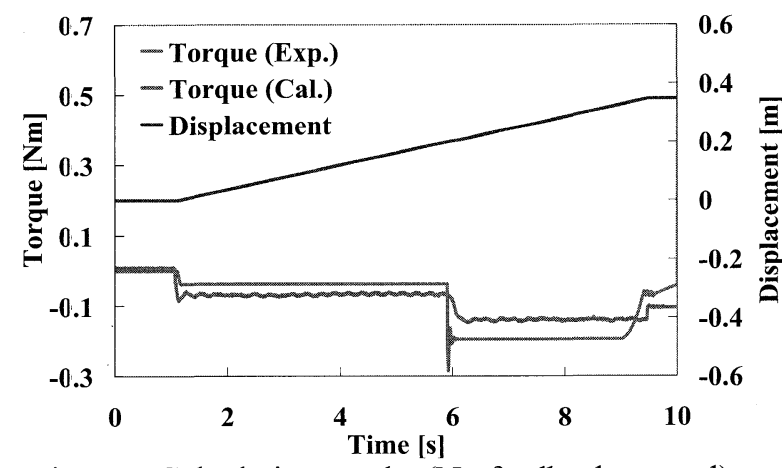

Figure 5 Calculation results (No feedback control)

\section{VERIFICATION OF SERVOMOTOR TORQUE REDUCTION BY EXPERIMENT}

Experimental parameters are shown in Table 2. Figures 6,7 and 8 show the maximum torques that act on the servomotor when feedback control was not performed and Figures 9, 10 and 11 show the maximum torques that act on the servomotor when feedback control was performed.

When feedback control was not performed, the rise of the torques in sudden load variations exceeded the rated torque $0.3[\mathrm{Nm}]$ of the servomotor in almost all cases. However, when feedback control was performed, in the case that Mass 1 was $10 \mathrm{~kg}$ and $30 \mathrm{~kg}$ and Mass 2 was $10 \mathrm{~kg}$ or $20 \mathrm{~kg}$, the torque did not exceed the rated torque even when the rotating speed was $1500 \mathrm{rpm}$. Furthermore, even when Mass 1 was $50 \mathrm{~kg}$ however Mass 2 was $10 \mathrm{~kg}$, the servomotor worked within the rated torque even in the case that the rotating speed raised to $1000 \mathrm{rpm}$. Therefore, the feed back control method we have proposed in this study is effective for reduction of torques acting on a servomotor, the authors believe.

Table 2 Experimental Parameters

\begin{tabular}{|c|c|c|c|}
\hline No. & $\begin{array}{c}\text { Mass1 } \\
{[\mathrm{kg}]}\end{array}$ & Mass2 [kg] & $\begin{array}{c}\text { Rotational Vel. } \\
{[\mathrm{rpm}]}\end{array}$ \\
\hline 1 & 10 & $10,20,30$ & $250-2000$ \\
\hline 2 & 30 & $10,20,30$ & $250-2000$ \\
\hline 3 & 50 & $10,20,30$ & $250-2000$ \\
\hline
\end{tabular}

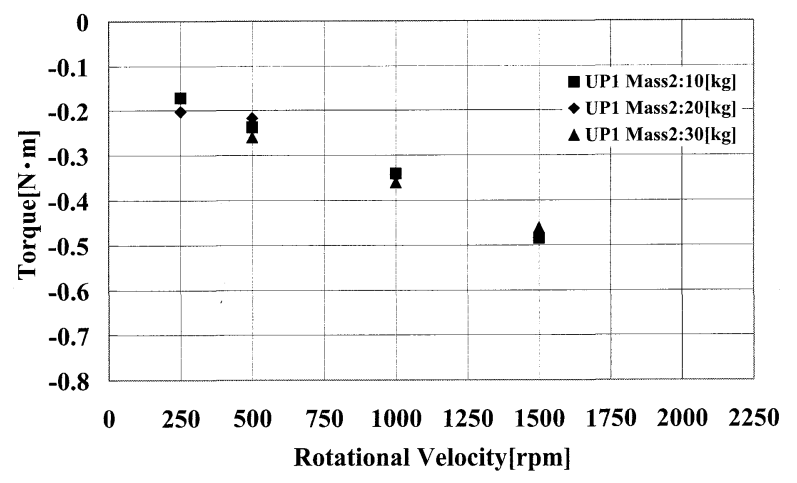

Figure 6 Mass 1 10kg (without control)

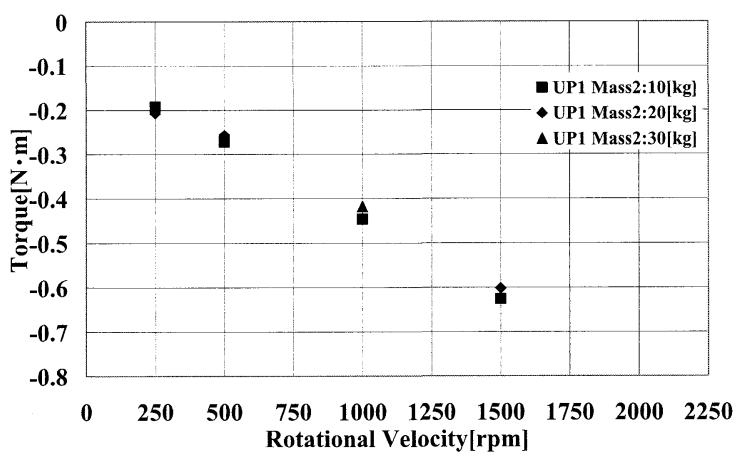

Figure 7 Mass $130 \mathrm{~kg}$ (without control)

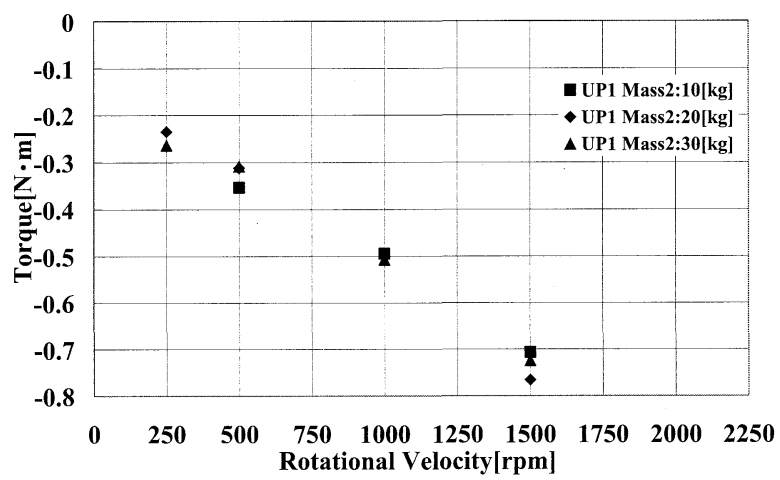

Figure 8 Mass $150 \mathrm{~kg}$ (without control)

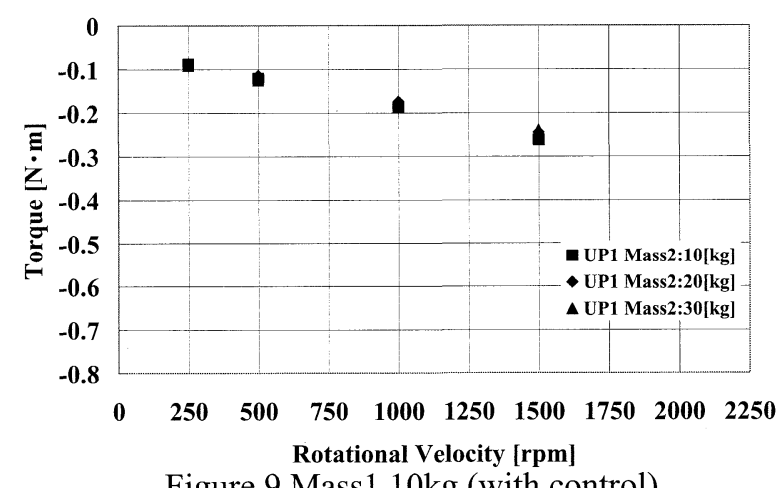

Figure 9 Mass $110 \mathrm{~kg}$ (with control)

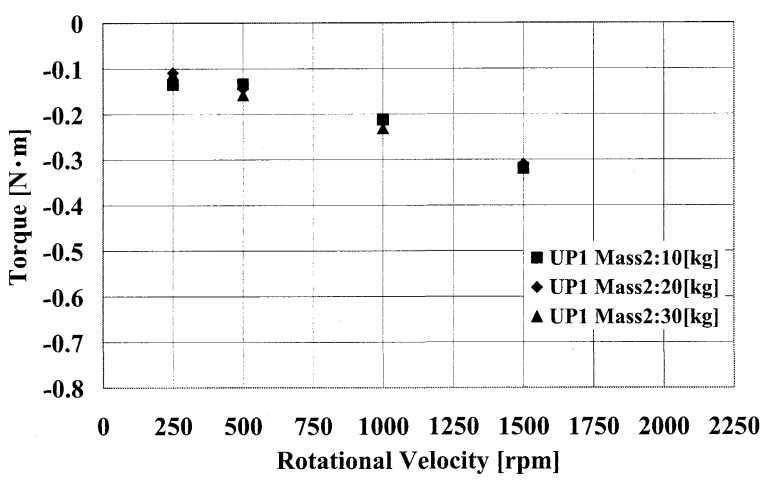

Figure 10 Mass $130 \mathrm{~kg}$ (with control) 


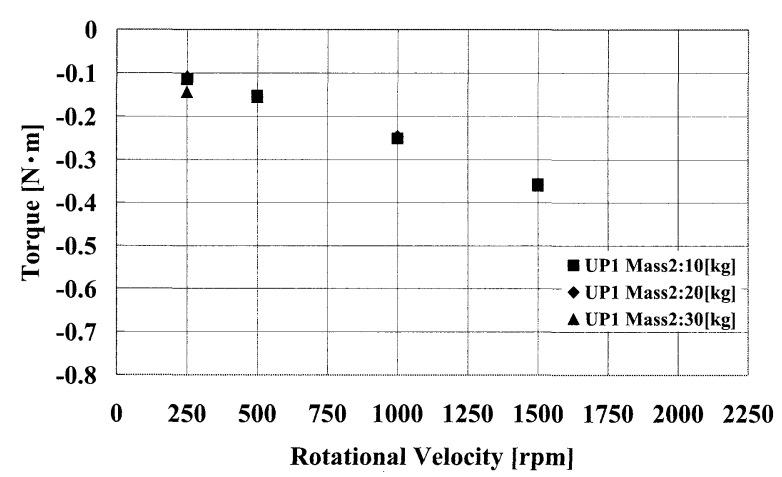

Figure 11 Mass $150 \mathrm{~kg}$ (with control)

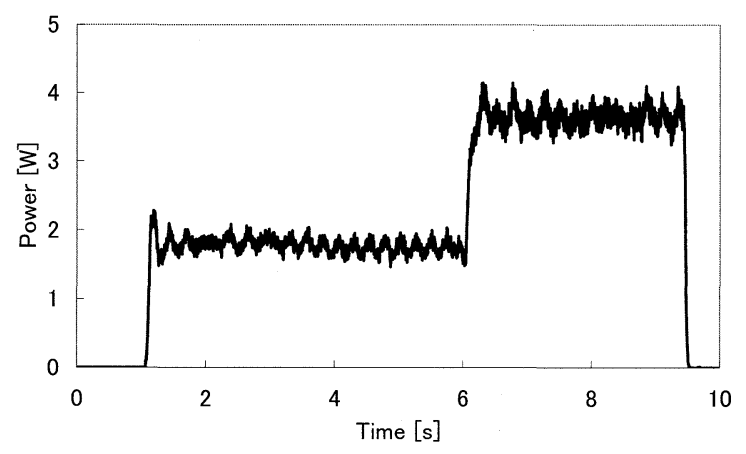

Figure 12 Power consumption (with control)

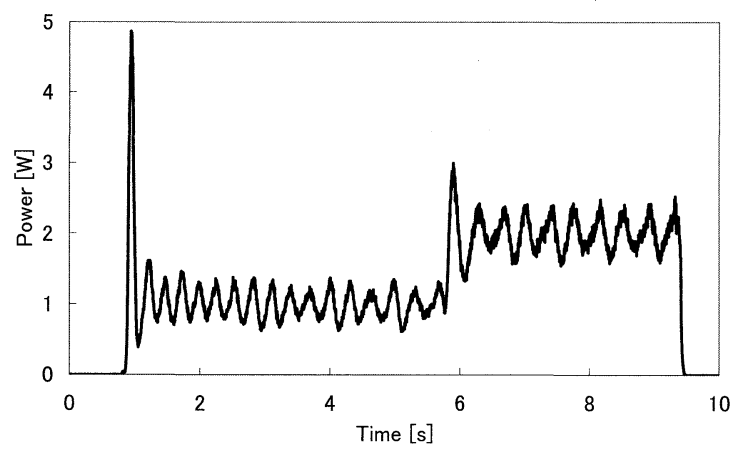

Figure 13 Power consumption (without control)

Table 3 Energy consumption

\begin{tabular}{|c|c|}
\hline With control & $12.4[\mathrm{~J}]$ \\
\hline Without control & $21.1[\mathrm{~J}]$ \\
\hline
\end{tabular}

The time dependencies for energy consumption of the servomotor with and without feedback control are shown in Figure 12 and Figure 13, respectively. When the actuator was driven using feedback control, large power is consumed during the starting period and pressure fluctuation becomes large. It is caused by time delay of the pressure control using feedback control.
Compared these two results, smaller amount of power is consumed under the feedback control. Table 3 shows energy consumptions during one stroke. Energy consumption of the servomotor with feedback control is half of that without feedback control. Therefore, it has been found that torques acting on a servomotor can be reduced by this control method.

\section{CONCLUSION}

We have proposed a feed back control method for an electro-pneumatic hybrid actuator. An analytical model of an actuator control system was already proposed however we have reverified its adequacy. Furthermore, as a result of the experiment for effects of the feed back control method, it has become able to operate the actuator within the rated torque range of a servomotor. The above result has revealed that it has become able to control a servomotor at the minimum value continuously. Moreover, it has been found that torques acting on a servomotor can be reduced by this control method.

This study has been supported by SMC Co., Ltd. for experimental equipment and so on. We would like to thank here for their cooperation.

\section{REFERENCES}

1. Shih, M. and Luor, N., Self-tuning Neural Fuzzy Control the Position of a Pneumatic Cylinder Under Vertical Load. Proc of $6^{\text {th }}$ FLUCOME, Sherbrooke CANADA, CD-ROM, 2000.

2. Zhang, B., Bondgraph Modeling and Simulation of Dynamic Characteristics of a Pneumatic System with an Air Cushion Cylinder, $5^{\text {th }}$ JFPS International Symposium, 2002, pp. 339-342.

3. Sakurai, Y., Tanaka, K. and Nakada, T., Dynamic Characteristic On An Electro-Pneumatic Hybrid Positioning System, $7^{\text {th }}$ Int. Symp. on Fluid Control, Measurement and Visualization, 2004

4. Higo, H., Sakurai, Y., Nakada, T., Tanaka, K. and Nagayama, K., Dynamic Characteristic and Power Consumption on an Electro-Pneumatic Hybrid Positioning System, The 6th JFPS International Symposium on Fluid Power TSUKUBA, CDROM, 2005

5. Wylie E. B. and Streeter V. L., Fluid Transient in Systems, PRENTICE HALL 1993, pp. 2-9.

6. Rosenberg R.C. and Karnopp, D.C., Introduction to Physical System Dynamics, McGraw-Hill, 1983.

7. Thoma J., Simulation by Bondgraphs, Springer-Verlag, 1990. 